\title{
Situación actual de la Oncología Quirúrgica y su integración con otras disciplinas
}

Durante muchos años, la Cirugía ha sido el único tratamiento frente al cáncer. Así, tradicionalmente la extirpación quirúrgica en mayor o menor amplitud ha sido una necesidad ineludible para intentar conseguir la curación de los tumores. Con la aplicación lineal de los conceptos de diseminación bacteriológica al ámbito tumoral, se diseñaron estrategias de grandes resecciones de órganos que incluían también sus redes ganglionares de drenaje. Estas resecciones fueron cada vez más amplias tras disponer de mejores antisépticos y anestésicos, hasta conllevar incluso mutilaciones importantes.

A mediados del siglo XX los conocimientos obtenidos de resultados de grupos cooperativos, la mayor parte retrospectivos, mostraron que las mayores resecciones no siempre mejoraban la supervivencia. Posteriormente, la puesta en marcha de campañas para el diagnóstico precoz ha probado su eficacia en algunas neoplasias, algo que tradicionalmente se había sospechado. Asimismo, los cambios producidos en la doctrina oncológica tradicional, entre los que destaca el abandono del concepto del mecanicismo escalonado, hizo perder potencia al tratamiento locorregional como principal estrategia para mejorar la supervivencia. Paralelamente, el mundo de la biología ha irrumpido con fuerza en un intento de comprender mejor la enfermedad neoplásica, aunque todavía no está suficientemente desarrollado para tener implicaciones terapéuticas.

El establecimiento paulatino de terapias multimodales, además de mejorar los resultados a largo plazo, ha permitido la creación de grupos asistenciales en las distintas disciplinas lográndose una mayor especialización y dedicación a tumores específicos de órganos o sistemas. De esta manera, la figura del especialista en Oncología Quirúrgica se ha ido imponiendo en el ámbito oncológico, como referente de mayor eficacia. Con ello surge el que, entre los quirúrgicos, la especialización oncológica se vaya dando con mayor frecuencia no sólo en el terreno del cáncer, sino incluso dentro de éste en órganos o sistemas específicos, lo que además de una mejor coordinación con otros especialistas oncólogos ha permitido disminuir la morbimortalidad y mejorar la supervivencia de los pacientes.

Este devenir llevó a que en 1982 desde diversas especialidades quirúrgicas, mayoritariamente cirujanos generales y digestivos, se creara la Sociedad Española de Cirugía Oncológica (SECO). Durante casi 20 años, con un meritorio escaso número de miembros, sus actividades han estado realizándose de forma integrada en el mundo quirúrgico general con puntuales apariciones en los Congresos de la Federación de Sociedades Españolas de Oncología (FESEO). Entre los objetivos de la Junta Directiva actual cuando fue elegida estaban el aumentar el número de miembros y la mayor penetración en el mundo oncológico. Ambos se han cumplido, habiéndose casi triplicado el número de miembros y haber participado integrados en Reuniones y Congresos. Las participaciones en esta Revista son buen ejemplo de ello. Otro objetivo no menos importante era el cambio de nombre de la Sociedad, al de Oncología Quirúrgica, lo que recientemente se ha aprobado en la XXVIII Asamblea General por varios motivos. En primer lugar, el término de Cirugía Oncológica sugería que la pertenencia a la Sociedad estaba limitada a los cirujanos generales y digestivos, cuando es evidente que otras especialidades quirúrgicas también abordan la cirugía oncológica en sus competencias. Por ello, el término de oncólogo quirúrgico abre más las puertas a que ginecólogos, otorrinos, urólogos, plásticos, torácicos, etc., puedan integrarse en la Sociedad, como así ha sido. Actualmente todas estas especialidades tienen presencia en la SEOQ. En segundo lugar, la convergencia internacional, con el uso de terminologías anglosajonas, favorece este cambio. La integración en la ESSO (European Society of Surgical Oncology), en la que en este momento estamos inmersos, abunda en este sentido. Por último, el acrónimo SECO, nos llevaba a continua confusión con el de Sociedad Española de Cirugía de la Obesidad, lo que con frecuencia daba lugar a equívocos en el momento de convocatorias para Reuniones y Congresos. Todos estos planteamientos han sido muy bien recibidos por los oncólogos quirúrgicos.

Con este cambio de nombre propuesto y aprobado, que ya ha sido registrado en el Ministerio, pretendemos una mayor integración de los especialistas quirúrgicos oncológicos con el resto de especialidades oncológicas no quirúrgicas, con participación activa en las referidas unidades, comités o grupos cooperativos, lo que en definitiva redundará en una mayor eficacia terapéutica para nuestros pacientes.

Carlos Vázquez Albaladejo Instituto Valenciano de Oncología Valencia 